\section{References}

Blackburn, R., Crelun, M. C., Morgan, E. M., et al (1990) Prevalence of personality disorder in a special hospital population. Journal of Forensic Psychiatry. 1, 43-52.

CHISwick. D. (1987) Managing psychopathic offenders: a problem that will not go away. British Medical Journal. 285. 159-160.

- (1992) Compulsory treatment of patients with psychopathic disorder: an abnormally aggressive or seriously irresponsible exercise? Criminal Behaviour and Mental Health, 2. 106-113.

CoID. J. (1987) Managing psychopathic offenders. British Medical Journal, 296, 606.

- (1992) DSM-III diagnosis in criminal psychopaths: a way forward. Criminal Behaviour and Mental Health, 2. 78-79.

COOKE. D. J. (1994) Psychological Disturbance in the Scottish Prison System: Prevalence. Precipitants and Policy. Edinburgh: Scottish Prison Service.

- (1996) Psychopathic personality in different cultures: What do we know? What do we need to find out? Journal of Personality Disorders, 10, 23-40.

- (1997a) Psychopaths: oversexed, overplayed, but not over here? Criminal Behaviour and Mental Health. 7. 3-11.

- (1997b) Cross-cultural aspects of psychopathic personality disorder. In Psychopathy. Theory. Research and Implications for Society (eds D. J. Cooke. A. Forth \& R. D. Hare). Dordrecht: Kluwer.

COPE. R. V. (1993) A survey of forensic psychiatrists' views on psychopathic disorder. Joumal of Forensic Psychiatry, 4, 215-236.
Davidson. M., Humphreys, M. S.. Johnstone. E. C., et al (1995) Prevalence of psychiatric morbidity among remand prisoners in Scotland. British Journal of Psychiatry. 167, 545-548.

GROUNDS, A. T. (1987) Detention of 'psychopathic disorder' patients in special hospitals. Critical issues. British Journal of Psychiatry. 161, 474-478.

HARE, R. D. (1980) A research scale for assessment of psychopathy in criminal populations. Personality and Individual Differences, 1. 111-119.

HUMPHREYS, M. S. (1997) A national survey of nonconsultant grade psychiatrists' knowledge of current mental health legislation in Scotland. Psychiatric Bulletin, 21, 631-635.

ScotTish Home and Health Department (1977) State Hospital, Carstairs. Report of Public Local Inquiry into Circumstances Surrounding the Escape of Two Patients on 30 November 1976 and into Securty and Other Arrangements at the Hospital. Edinburgh: HMSO.

TAYLOR, P. J., BUTWELL. M., DACEY, R., et al (1991) Within Maximum Security Hospitals: A Survey of Need. London: Special Hospitals Authority.

THOMSON, L. J.. BogUE. J. P.. HuMPHREYS, M. S., et al (1997) The State Hospital survey: the circumstances of patients detained in conditions of special security in Scotland. Joumal of Forensic Psychiatry. 8. 263-284.

Martin S. Humphreys. Senior Lecturer in Forensic Psychiatry, Reaside Clinic, Birmingham Great Park, Rubery. Birmingham B45 9BE

\title{
Therapeutic community provision at regional and district levels
}

\author{
Steffan Davies, Penelope Campling and Kerry Ryan
}

\begin{abstract}
Aims and method The aim of the study was to investigate changes in service utilisation following therapeutic community treatment for patients with severe personality disorder. The study examined service usage, in the form of acute psychiatric admissions, of a series of 52 admissions to a residential therapeutic community in the three years before and year after admission.

Results There was a reduction in the mean duration of acute psychiatric admissions after treatment, this was greater for extra-contractual referral patients than local district patients.

Clinical implications This study replicates results from previous studies. It also suggests that more accessible local services may be able to intervene earlier in patients' psychiatric careers preventing heavy use of acute services. We argue for greater provision of
\end{abstract}

therapeutic community treatment for severe personality disorder.

There has been much interest in recent years in the treatment of personality disorder in therapeutic communities. Recent research gives some support for the efficacy (Dolan \& Coid, 1993) and cost-effectiveness (Chiesa et al, 1996, Dolan et al, 1996) of this form of treatment, although no controlled trials exist for practical, ethical and financial reasons (for a fuller discussion see Lees, 1999). Much of the published research has come from the Henderson and the Cassel Hospitals which offer supra-regional services and are largely funded by extra-contractual referrals (ECRs) (Dolan \& Norton, 1992). The patients 
referred to these units are highly selected and often have a long wait for funding to be agreed, if any is forthcoming. The recent joint Department of Health/Home Office Review of Services for Mentally Disordered Offenders Sub-Committee on Psychopathic Disorder recommended the provision of more therapeutic communities (Department of Health \& Home Office, 1994). Effective treatment of patients with severe personality disorder (SPD) may also contribute to the attainment of the 'Health of the Nation' targets, particularly on suicide (Norton, 1992). There are a number of other National Health Service (NHS) units operating as therapeutic communities, either as in-patient services like our own (Francis Dixon Lodge) or as day services, such as Winterbourne in Berkshire (Knowles, 1997). While there is good evidence that the supraregional services are clinically- and cost-effective, the optimum level of therapeutic community provision across the country is not known.

There has been a recent debate in the British Journal of Psychiatry over the optimum style of service. Units operating as day services are limited in the area they can serve by daily travelling times and may have problems containing some of the more disturbed patients treated by in-patient units (Campling \& Davies, 1997). They are, however, much cheaper to run as they do not require 24-hour cover, have reduced hotel costs (Haigh \& Stengen, 1996) and can be more easily integrated with other services (Knowles, 1997). In-patient units can provide services to a much greater geographical area and can contain higher levels of disturbance but are inevitably more costly. The follow-up of patients on discharge (Norton \& Hinshelwood, 1996) is also more difficult.

The cost-offsets of therapeutic community treatments are predominantly through reduced psychiatric admissions and periods of imprisonment but also in the consumption of general medical, accident and emergency, general practitioner (GP), probation and social services. Costoffset is in addition to the 'health gain' in clinical, psychological and social terms. Those referred for ECR-funded treatment are likely to be high consumers of psychiatric or criminal justice services and skew the cost analysis in favour of supra-regional services. Services provided at a more local level are likely to get fewer high service users and it is therefore more difficult to demonstrate cost-offsets. Local and more accessible services, which avoid the long delays of obtaining ECR funding, may, however, be able to intervene earlier and create additional gains. This may prevent costly acute in-patient stays aimed at reducing risk, which generally appear to be of little therapeutic benefit to this group, and are sometimes detrimental (Norton \& Hinshelwood, 1996).
Our 16-bed service is funded by the district health authority but takes around $20 \%$ of its referrals as ECRs, mainly from the Trent Region but from as far away as South Wales. This allows comparison of the psychiatric service use of a district and ECR group which may throw some light on the ideal levels of service for a given population. Leicestershire, as the largest health authority in the country (population 930 000), is in a better position than most to support a district in-patient psychotherapy unit. The potentially difficult transition at discharge is reduced by a group (Next Step) beginning six weeks before discharge and continuing for six months. Francis Dixon Lodge also offers on-going follow-up in the form of an ex-resident drop-in group which meets weekly for those in crisis. In therapeutic terms the treatment at Francis Dixon Lodge is similar to the Henderson Hospital in that therapy takes place exclusively in group settings in contrast to the individual therapy provided at the Cassel. The previous service usage is also more like the Henderson Hospital with many patients being heavy users of general psychiatry in-patient services in contrast to the greater usage of out-patient psychotherapy for Cassel patients (Chiesa et al, 1996). The diagnostic status of the patients and their severity of personality disorder remains open to debate. Using DSM-III-R criteria (American Psychiatric Association, 1987) and a self-report questionnaire, patients at the Henderson received a mean of 6.04 personality disorder diagnoses. ICD-10 (World Health Organization, 1992) uses the most clinically significant personality disorder diagnosis, and does not normally permit multiple diagnoses. Standardised measures of severity, particularly for people with severe personality disorder do not exist, although work in this area is underway (e.g. Tyrer \& Johnson, 1996).

\section{The study}

A series of consecutive admissions ( $n=52)$ between 1 January 1993 and 31 December 1995 was identified from admission records at Francis Dixon Lodge. (One patient who had a very brief admission of two days from outside the region and for whom information was incomplete was excluded.) The psychiatric admissions of these patients were traced for three years before admission and after discharge from Francis Dixon Lodge until 30 June 1997 (further followup is planned). For Leicestershire patients this was done through the Patient Administration System (PAS) and for ECR patients by contacting their referring consultants and the psychiatric units in the area to which they were discharged. This was cross-checked with their GPs when necessary. By the 30 June 1997, 47 of the 52 
patients had been discharged for at least one year. Data analysis used SPSS 7.5.

\section{Findings}

The mean age of patients was 27.3 years (range 19-44). Thirty patients were women and 22 men. Forty patients were from Leicestershire and the remaining 12 ECR.

\section{Diagnoses}

ICD-10 diagnoses were made by the clinical team, usually at each patient's three-week review (one patient had a very brief admission and insufficient information was available to make a diagnosis). The predominant ICD-10 personality disorder diagnosis was F60.3 (emotionally unstable, $86.5 \%)(74 \%$ of Henderson patients were diagnosed as suffering DSM-III-R borderline personality disorder). Other personality disorder diagnoses were: paranoid, $3.8 \%$; dependent, 3.8\%; schizoid, 1.9\%; and anakastic, $1.9 \%$. Secondary ICD-10 diagnoses were diagnosed for 61.5 and $17.3 \%$ tertiary. Forty per cent met criterla for harmful use or dependence on alcohol and/or drugs, $25 \%$ for eating disorders and $13 \%$ recurrent depression or dysthymia. There were no significant differences between ECR and district groups in terms of diagnosis, gender or historical factors on $\chi^{2}$ testing. The ECR patients had a mean age of 24.5 (s.d.=3.9) which was significantly different from the Leicestershire mean of 28.1 (s.d.=6.8), $t$-test for equality of means, unequal, $P=0.026$.

\section{Service usage}

By 30 June 1996, 47 first admissions to Francis Dixon Lodge had been completed. The mean length of stay for the 12 ECRs was 265 days (total 3178 days, cost $\$ 418924$ ) and for the 35 Leicestershire district patients 180 days (total 6310 days, cost $\$ 831$ 924). By 30 June 1997 two of the ECR patients had been readmitted to Francis Dixon Lodge for a total of $\mathbf{4 2}$ days, four of the Leicestershire patients had been readmitted for a total of $\mathbf{5 4 5}$ days.

\section{Cost-offset}

For ECR patients the average cost of acute admissions in the year before treatment at Francis Dixon Lodge was $\$ 9499$. The average cost of Francis Dixon Lodge admission was 265 days at $£ 131.82$ a day $=£ 34932$. The average cost in the first year after admission of 7.2 days at $£ 128.94$ a day $=£ 928$. Consequently, the cost-offset in first year was $£ 9499-£ 928=£ 8571$. The time to fund treatment was ( $£ 34932 / £ 8571$ ) four years.

The Henderson costs (1993-94) £110 daily; Thames acute beds (1992-93) £153.2; (1993-94)
Table 1. History on admission to Francis Dixon Lodge

\begin{tabular}{ll}
\hline & $\%$ \\
\hline Overdose & 75 \\
Self-mutilation & 67 \\
Other self-harm & 33 \\
Violence to others & 15 \\
Sexual abuse & 62 \\
Physical abuse & 46 \\
\hline
\end{tabular}

$£ 179$, and time to fund treatment approximately two years (from Dolan et al, 1996).

\section{Comment}

The results show important differences between local (Leicestershire) and ECR patients (see Tables 2 and 3). The ECR patients had spent longer periods on general psychiatry wards in the three years preceding admission to Francis Dixon Lodge than Leicestershire patients. Our findings were similar to those of the Henderson Hospital (Dolan et al, 1996), who found a mean bed occupancy of 71 days in the year before referral, whereas our ECR group occupied an average of 74 days. In the year of follow-up after admission to the Henderson there was a mean bed occupancy of 7.5 which is almost identical to the 7.2 for our ECR sample. The less striking changes for Leicestershire district patients suggests that there is a gradation of severity, in terms of in-patient usage, from regional/supraregional more selected ECR patients to district referrals. For ECR patients the cost-offset calculated for the year before and after treatment would lead to treatment funding itself in about four years. For the ECR group, $43 \%$ of the total acute occupancy over the preceding three years occurred in the year before admission. This would argue against a ceiling-floor effect where patients are referred at their worst and improvement which may have occurred naturally is ascribed to treatment. Although using more bed days in the year before admission substantial usage had also occurred in the second and third years before admission.

The difference between the ECR and district group is of interest. In the three-year period before admission they occupied an average of 168 and 57 occupied bed days respectively. The year before admission this accounted for $43 \%$ of the three year total for the ECR group but $63 \%$ for the district group. Referral to a district service, which is more familiar to referrers and does not involve obtaining ECR funding, may promote earlier treatment and prolonged general admissions may be avoided. The easy availability of alternative treatment facilities may also 
Table 2. General psychiatry admissions three and one year before admission to Francis Dixon Lodge

\begin{tabular}{lccccc}
\hline & Days & Mean (s.d.) & Median & Cost per day & Total cost \\
\hline Three year & & & & & \\
$\quad$ Leicestershire & 2272 & $56.3(98.8)^{\prime}$ & 5.5 & $£ 110.14$ & $£ 250238$ \\
ECR & 2020 & $168(184)^{\prime}$ & 10.5 & $£ 128.94$ & $£ 260459$ \\
One year & 1420 & $36(52)$ & 5.5 & $£ 110.14$ & $£ 156399$ \\
$\quad$ Leicestershire & 884 & $74(112)$ & 14.5 & $£ 128.94$ & $£ 113983$ \\
ECR & 2304 & $44.3(70.9)$ & 5.5 & & $£ 270382$ \\
Total & & & & & $\$ 248133$ \\
$\quad$ Total of patients with follow-up & 2102 & $44.7(71.8)$ & 6 & & \\
data $(n=47)$ &
\end{tabular}

ECR, extra-contractual referral.

1. Independent samples $t$-test showed a significant difference $(0.009)$ between the mean length of previous admissions for ECR and district patients after data reduction by standardised $z$ scores.

2. Paired sample t-tests showed no significant differences between the mean admissions one year pre- and postadmission to Francis Dixon Lodge for the total sample, district and ECR groups after data reduction ( $z$ scores).

3. The costs are 1996-97 contract costs for Leicestershire Mental Health Services NHS Trust/Leicestershire Health and average costs for Trent Region for ECRs (Francis Dixon Lodge $=\{131.82$, Leicestershire acute $=\{110.14$, Trent acute $=£ 128.94$ ) further details available from the author upon request.

Table 3. General psychiatry admissions in the year after admission to Francis Dixon Lodge

\begin{tabular}{lllllll}
\hline & Patients & Days & Mean (s.d.) & Median & Cost per day & Total cost \\
\hline Leicestershire & 35 & 423 & $12.1(24.1)$ & 0 & $£ 110.14$ & $\$ 46589$ \\
ECR & 12 & 86 & $7.2(12.1)$ & 0 & $\$ 128.94$ & $\$ 11089$ \\
Total & 47 & 509 & $10.8(21.7)$ & 0 & & $\$ 57678$ \\
\hline
\end{tabular}

ECR, extra-contractual referral.

1. Paired sample t-tests showed no significant differences between the mean admissions one year pre- and postadmission to Francis Dixon Lodge for the total sample, district and ECR groups after data reduction (z scores).

2. The costs are 1996-97 contract costs for Leicestershire Mental Health Services NHS Trust/Leicestershire Health and average costs for Trent Region for ECRs (Francis Dixon Lodge $=£ 131.82$, Leicestershire acute $=£ 110.14$, Trent acute $=£ 128.94$ ) further details available from the author upon request.

influence management by general psychiatrists. The availability of a local alternative to prolonged acute admission gives more treatment options and better opportunities to manage severely personality disordered patients constructively. One possibly negative result is that as there is less invested in the referral by referrer and patient (as there are less obstacles and easier exits) district patients are less likely to complete their treatment suggested by reduced average stay (180:265). The average stay of the four district patients who were re-admitted was 132 days, suggesting that some may have completed treatment after an abortive first admission.

This evidence has a number of implications for the provision of in-patient psychotherapy for patients with severe personality disorder. Regional/supra-regional services, with more selected patients and greater barriers to referral, have demonstrated cost-offsets implying treatment is self-funding in the medium-term. The ECR patients in our sample also demonstrate a costoffset, although the costs on which these assumptions are based are different. (For further discussion of economic evaluations of therapeutic communities see Davies (1999).) It is likely there- fore that there are sufficient patients for every region to justify an in-patient unit for SPD patients as rates of SPD are likely to be similar throughout the UK. This is only likely to be feasible with a degree of central planning and an alternative funding mechanism to the current ECR system. The much higher proportion of inpatient usage in the year before admission in the patients from district rather than regional origin suggests a preventative effect for in-patient therapeutic community treatment earlier in patients' psychiatric career. The easy availability of a district service is also likely to lead to less disturbed patients being referred, possibly indicated by the greater mean age of the district sample. It is possible that some of these could be effectively managed in local day services (Vaglum et al, 1990; Haigh \& Stengen, 1996). We are currently experimenting with the use of day attendance towards the end of patients' treatment at Francis Dixon Lodge.

The reduction in usage of psychiatric in-patient beds following treatment of severe personality disorder in a therapeutic community adds to the growing body of evidence for the efficacy of therapeutic community treatment for this group 
of patients. The demonstration that a service can be effective on a regional level suggests that there should be provision of an in-patient unit for SPD patients in every region. The differences between ECR and district referrals suggest that locallybased, easily-accessible therapeutic community facilities may reduce, or prevent, usage of general psychiatry beds by this patient group relieving pressure on these overburdened services.

\section{Acknowledgements}

We gratefully acknowledge the help and support of the Leicestershire Mental Health Services NHS Trust, Clinical Audit and Improvement Group and Dr Sue Read, Leicestershire Health, Mental Health Purchasing Team.

\section{References}

American PSyChiatric Assoclation (1987) Diagnostic and Statistical Manual of Mental Disorders (3rd edn. revised). Washington. DC: APA

Campung. P. M. \& Davies, S. (1997) In-patient psychotherapy. British Journal of Psychiatry. 170. 90 91.

ChIESA, M., ICCOPONI, E. \& Morris, M. (1996) Changes in health service utilization by patients with severe personality disorders before and after inpatient psychosocial treatment. British Journal of Psychotherapy, 12, 501-512.

DAvIES. S. (1999) Does every district need a TC: survival and growth in the marketplace? In Therapeutic Communities: Past. Present and Future (eds R. Haigh \& P. Campling). pp. 223-234. London: Jessica Kingsley Publishers.

DEPARTMENT OF HEALTH \& HOME OFFICE (1994) Review of Services for Mentally Disordered Offenders and Others with Similar Needs. Report of the Sub-Committee on Psychopathic Disorder (The Reed Report). London: HMSO.
DOLAN, B. \& NorTON. K. (1992) One year after the NHS Bill: the extra contractual referral system and the Henderson Hospital. Psychiatric Bulletin, 16. 745-747.

- \& CoID. J. (1993) Psychopathic and Antisocial Personality Disorders: Treatment and Research Issues. London: Gaskell.

- WARRen. F. M. Menzies, D., et al (1996) Cost offset following specialist treatment of severe personality disorders. Psychiatric Bulletin, 20, 413-417.

HAigh, R. \& STENGEN, G. (1996) In-patient psychotherapy. British Journal of Psychiatry. 168. 524.

KNOWLES, J. (1997) The Reading Model: an integrated psychotherapy service. Psychiatric Bulletin. 21, 84-88.

LEES, J. (1999) Researching therapeutic communities. In Therapeutic Communities: Past. Present and Future (eds R. Haigh \& P. Campling). pp. 207-222. London: Jessica Kingsley Publishers.

NoRTON, K. R. W. (1992) Health of the Nation: the impact of personality disorder on 'key areas'. Postgraduate Medical Joumal. 68, 350-354.

- \& HINSHELWOOD, R. D. (1996) Severe personality disorder: treatment issues and selection for in-patient psychotherapy. British Journal of Psychiatry. 168. 723-731.

TYRER, P. \& JoHNSON. T. (1996) Establishing the severity of personality disorders. American Journal of Psychiatry. 153. 1593-1597

VAGlum, P.. Fris, S., IrION. T., et al (1990) Treatment response of severe and non severe personality disorders in a therapeutic community day unit. Journal of Personality Disorders, 4, 161-172.

WORLD HEALTH ORganization (1992) The Tenth Revision of the International Classification of Diseases and Related Health Problems (ICD-10).Geneva: WHO.

Steffan Davies, Senior Registrar, Forensic Psychiatry, "Penelope Campling, Consultant Psychotherapist, and Kerry Ryan, Audit Assistant, Francis Dixon Lodge, Gipsy Lane. Leicester LE5 5OD

*Correspondence

\title{
Monitoring lithium treatment: evaluation of current management
}

\author{
Anita Kotak, Ann Elaine Arnold and Peter Frost
}

Aims and method A postal survey of 81 general practitioners (GPs) who were involved in lithium monitoring was undertaken, to compare their views on lithium therapy with their monitoring practice, and with the practice of psychiatrists.

Results Forty-seven replied (response rate 50.6\%). There was considerable variation in GP knowledge of lithium therapy. GPs made fewer requests but wanted more information.

Clinical implications Written reminders and information on lithium would be useful to GPs.

Lithium has shown to be effective in the treatment of mania, the prophylaxis of bipolar 